\title{
c-mos Expression in Mouse Oocytes Is Controlled by Initiator-Related Sequences Immediately Downstream of the Transcription Initiation Site
}

\author{
SUBRATA K. PAL, ${ }^{1,2}$ SANDRA S. ZINKEL, ${ }^{1,2}$ ANN A. KIESSLING, ${ }^{3,4}$ AND GEOFFREY M. COOPER ${ }^{1,2 *}$ \\ Dana-Farber Cancer Institute, 44 Binney Street, ${ }^{1}$ Faulkner Center for Reproductive Medicine, Faulkner Hospital, ${ }^{3}$ \\ and Departments of Pathology ${ }^{2}$ and of Surgery, ${ }^{4}$ Harvard Medical School, Boston, Massachusetts 02115
}

Received 16 June 1991/Accepted 25 July 1991

\begin{abstract}
We have employed transient expression assays to analyze the sequences that direct c-mos transcription in mouse oocytes. Plasmids containing the chloramphenicol acetyltransferase (CAT) gene fused to either a 2.4-kb or a 731-bp fragment from the $5^{\prime}$-flanking region of c-mos produced similar levels of CAT activity when injected into nuclei of growing oocytes. BAL 31 deletions revealed that sequences up to 20 bp upstream of the major transcription start site could be removed without any significant loss of CAT activity. Promoter activity only decreased when these deletions closely approached the transcription start site, which was mapped at 53 nucleotides upstream of the first ATG in the c-mos open reading frame. On the other hand, deletion of sequences within 20 nucleotides downstream of the transcription initiation site resulted in a 10 -fold reduction in CAT expression. A similar decrease in promoter activity was observed as a result of point mutations in these $5^{\prime}$ untranslated sequences. Thus, sequences immediately downstream of the transcription start site, including a consensus sequence (PyPyCAPyPyPyPyPy) present in the initiator elements of several genes, appear to regulate c-mos expression in mouse oocytes. Reverse transcription-polymerase chain reaction analysis of RNA from injected oocytes showed that this regulation is manifest at the transcriptional level. Expression of c-mos in mouse oocytes thus appears to be directed by a simple promoter consisting only of sequences immediately surrounding the transcription start site, including an initiator element in the untranslated leader.
\end{abstract}

While some proto-oncogenes are expressed in many types of proliferating cells, others display more restricted patterns of expression, suggesting that they function in specific developmental pathways. c-mos, in particular, is of interest in that its major sites of expression appear to be limited to male and female germ cells of the mouse and several other species $(11,20,26,30,33,35)$, suggesting a specific role for this proto-oncogene in meiosis. Indeed, microinjection of Xenopus and mouse oocytes with antisense oligonucleotides has demonstrated that c-mos is required for meiosis in both species $(23,25,33)$, apparently acting as a cytostatic factor in Xenopus eggs (34) and functioning to maintain activity of maturation-promoting factor by stabilizing cyclin B in mouse eggs (22).

The regulation of c-mos transcription is of interest both because of $i$ is distinct pattern of expression and because of its function in the meiotic cell cycle. The earliest stages of embryonic development are controlled by maternal RNAs that are specifically transcribed and stored in oocytes. In the mouse, c-mos is transcribed during oocyte growth, and high levels of the transcript (estimated to be on the order of 100,000 copies per cell) are accumulated in fully grown oocytes arrested at the diplotene stage of meiotic prophase $(11,20)$. Like other mouse maternal RNAs, the c-mos transcript is polyadenylated following the resumption of meiosis and is subsequently degraded at the two-cell stage $(10,19)$. The c-mos proto-oncogene thus appears to represent a maternal message that is specifically expressed in oocytes of a variety of vertebrates. As such, c-mos provides a model for studies of the regulation of maternal gene expression. However, the sequence elements that regulate

\footnotetext{
* Corresponding author.
}

transcription of c-mos or of other genes expressed in either mouse or Xenopus oocytes have not been identified.

S1 nuclease analysis has indicated that c-mos produces 1.7- and 1.4-kb transcripts in mouse testis and ovary, respectively $(30,31)$. The size difference is apparently due to tissue-specific utilization of different promoters. In the testis, the transcription initiation sites are clustered around $-280 \mathrm{bp}$, while in the ovary they have been mapped to around $-70 \mathrm{bp}$ with respect to the first ATG of the c-mos open reading frame (30). Neither of the two promoter regions contain TATA boxes, GC-rich tracts, or other identified transcriptional regulatory sequences.

We therefore utilized transient expression assays in microinjected oocytes to determine the cis-acting elements that regulate c-mos transcription. Deletion analysis and sitespecific mutagenesis indicate that sequences immediately surrounding the transcription initiation site are sufficient to direct c-mos expression in mouse oocytes. These regulatory sequences extend approximately $20 \mathrm{bp}$ downstream of the transcription start site and include sequences related to the initiator (Inr) element, recently identified in the mouse terminal deoxynucleotidyltransferase gene (36).

\section{MATERIALS AND METHODS}

RNA extraction and primer extension. RNA was extracted from ovaries of 20- to 23-day-old B6D2F1 mice essentially as described by Cathala et al. (5). Ovaries were homogenized in $5 \mathrm{M}$ guanidinium thiocyanate- $10 \mathrm{mM}$ EDT A-50 $\mathrm{mM}$ Tris- $\mathrm{Cl}$, $\mathrm{pH} 7.5-8 \%$ (vol/vol) $\beta$-mercaptoethanol. RNA was precipitated with $5 \mathrm{vol}$ of $4 \mathrm{M} \mathrm{LiCl}$ and washed with $5 \mathrm{vol}$ of $3 \mathrm{M}$ $\mathrm{LiCl}$. The RNA pellet was resuspended in $0.1 \%$ sodium dodecyl sulfate-1 $\mathrm{mM}$ EDTA-10 mM Tris- $\mathrm{Cl}$, $\mathrm{pH}$ 7.5. This was extracted with phenol-chloroform and precipitated with 
0.5 volume of saturated ammonium acetate and 2 volumes of ethanol. The pellet was redissolved in diethylpyrocarbonatetreated $\mathrm{H}_{2} \mathrm{O}$.

Primer extension analysis was performed by using a 15-nucleotide primer (5'-CAGGCTTAGAGGCGA-3') complementary to c-mos nucleotides +7 to +21 with respect to the ATG. Approximately $10^{5} \mathrm{cpm}$ of the labeled primer was hybridized to $40 \mu \mathrm{g}$ of total RNA by heating the mixture to $75^{\circ} \mathrm{C}$ for $5 \mathrm{~min}, 60^{\circ} \mathrm{C}$ for $25 \mathrm{~min}, 55^{\circ} \mathrm{C}$ for $20 \mathrm{~min}, 50^{\circ} \mathrm{C}$ for 25 min, and $25^{\circ} \mathrm{C}$ for $20 \mathrm{~min}$. The hybridized primer was elongated as described previously (15). The products were electrophoresed in a $7 \%$ polyacrylamide sequencing gel alongside a c-mos sequencing ladder generated with the same primer.

Plasmid DNAs. pSV3CAT is essentially pSV2CAT (12) in which the BamHI site was destroyed. pSVOCAT was derived from $\mathrm{pSV} 3 \mathrm{CAT}$ by replacing the $N$ deI-HindIII fragment containing the simian virus 40 (SV40) promoter with a 103-bp SacI-KpnI multiple cloning site (KS-polylinker) from the Bluescript $(+)$ plasmid. In addition, a 1.6-kb Xbal$B a m H I$ fragment from intron 10 of the c-raf-1 gene (4) was introduced between the XbaI and BamHI sites of the polylinker. This acts as a "stuffer" fragment to prevent readthrough transcription from pBR322 sequences, and transfection of pSVOCAT into NIH 3T3 cells did not produce any detectable chloramphenicol acetyltransferase (CAT) activity. A 731-bp $M n l$ I fragment ( -16 to -746 with respect to the mos ATG) from c-mos plasmid pMS1 (24) was inserted at the HindIII site of the pSVOCAT polylinker to construct the plasmid pmos731. The plasmid pmos 2400 contains approximately $2.4 \mathrm{~kb}$ of the c-mos 5'-flanking region, terminating in an $E c o \mathrm{RV}$ site of pMS1 (40), inserted in front of the CAT gene.

The plasmid pmos731 was linearized with BamHI or SalI to make deletions from the $5^{\prime}$ or $3^{\prime}$ end of the mos sequences, respectively, by digestion with BAL 31 nuclease. Deletion endpoints were determined by sequencing. The plasmid pmos 21 , which contains c-mos sequence extending from 21 nucleotides upstream of the major transcription start site to 16 nucleotides upstream of the ATG (flanked by SalI and $B a m H I$ restriction sites), was used for site-specific mutagenesis by replacing the BamHI-SalI fragment with synthetic oligonucleotides carrying mutations at specific bases. The plasmid pmos21-1, which contains 5' c-mos sequence extending from 21 nucleotides upstream of the transcription start site to the ATG, was similarly constructed with synthetic oligonucleotides from pmos 21 .

Oocyte isolation and culture. Growing oocytes were isolated from 18- to 20-day-old B6SJL mice (The Jackson Laboratory) essentially as described by Wassarman and Josefowicz (39). Ovaries were washed in Dulbecco's phosphate-buffered saline (DPBS) and incubated at $37^{\circ} \mathrm{C}$ for 15 to $20 \mathrm{~min}$ in the presence of $100 \mathrm{U}$ of collagenase (type III; Sigma), $50 \mu \mathrm{g}$ of hyaluronidase (type IV-S; Sigma) per ml, $150 \mu \mathrm{g}$ of 3-isobutyl-1-methylxanthine (IBMX) per ml, and 4 $\mathrm{mg}$ of bovine serum albumin per $\mathrm{ml}$. After incubation, the ovaries were gently punctured by using 28-gauge needles with the aid of a dissecting microscope. Growing oocytes which contained an intact germinal vesicle and were free of cumulus cells were harvested with a micropipet. Oocytes which appeared to be about 60 to $70 \%$ of the fully grown size were selected. These oocytes correspond to stage 4 of maturation (28) and are transcriptionally active (38). Approximately 30 to 40 such oocytes were obtained per mouse. The harvested oocytes were rinsed three times with DPBSIBMX-bovine serum albumin and transferred to either
Earle's balanced salt solution plus amino acids (18) or modified Ham's F-10 medium (14) supplemented with $15 \mu \mathrm{M}$ EDTA and $150 \mu \mathrm{M}$ IBMX. Oocytes were incubated at $37^{\circ} \mathrm{C}$ in $8 \% \mathrm{CO}_{2}(\mathrm{pH} 7.1$ to 7.2$)$.

Injection of oocytes. Plasmid DNA was reprecipitated three times with sodium acetate and ethanol and rinsed twice with $70 \%$ ethanol. The pellet was dried under vacuum and resuspended in injection buffer $\left(48 \mathrm{mM} \mathrm{K}_{2} \mathrm{HPO}_{4}, 4.5 \mathrm{mM}\right.$ $\mathrm{KH}_{2} \mathrm{PO}_{4}, 14 \mathrm{mM} \mathrm{NaH} \mathrm{PO}_{4}, 0.25 \mathrm{mM}$ EDTA, pH 7.2) to a final concentration of $0.1 \mathrm{mg} / \mathrm{ml}$. The DNA was centrifuged at approximately $15,000 \times g$ in an Eppendorf microcentrifuge for $60 \mathrm{~min}$ at $4^{\circ} \mathrm{C}$, and the supernatant was transferred to a clean Eppendorf tube.

DNA was loaded into an injection pipet with a diameter of 1 to $2 \mu \mathrm{m}$ by using a Picoinjector 100 (Medical Systems, Greenvale, N.Y.). From 25 to 30 oocytes were washed through DPBS-bovine serum albumin-IBMX and transferred to a drop of the same buffer under silicone oil. Oocytes were visualized by using Hoffman diffraction-interference contrast optics, and germinal vesicles (nuclei) were injected with approximately $5 \mathrm{pl}$ of a $0.1-\mathrm{mg} / \mathrm{ml}$ solution of plasmid DNAs. Injections were monitored to detect germinal vesicle swelling. The injected oocytes were cultured for $48 \mathrm{~h}$ in modified Ham's F-10 medium (14) supplemented with $150 \mu \mathrm{M}$ IBMX and $15 \mu \mathrm{M}$ EDTA. Oocyte survival was 50 to $70 \%$.

CAT assays of injected oocytes. CAT assays of injected oocytes were performed by using a single-vial method (21). Between 10 and 20 oocytes were harvested in $25 \mu \mathrm{l}$ of 100 $\mathrm{mM}$ Tris- $\mathrm{Cl}, \mathrm{pH} 7.8$, and subjected to four freeze-thaw cycles. The lysate was centrifuged at $4^{\circ} \mathrm{C}$ for $10 \mathrm{~min}$, and the supernatant was collected for a CAT assay. An aliquot ( 5 to

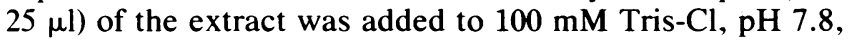
to give a total volume of $50 \mu \mathrm{l}$. The solution was heated at $65^{\circ} \mathrm{C}$ for $15 \mathrm{~min}$ and then cooled to room temperature. This was added to $200 \mu \mathrm{l}$ of a freshly prepared solution containing $100 \mathrm{mM}$ Tris- $\mathrm{Cl}, \mathrm{pH} 7.8,1.25 \mathrm{mM}$ chloramphenicol, and 0.25 $\mu \mathrm{Ci}$ of ${ }^{3} \mathrm{H}$-labeled acetyl coenzyme A (Dupont, NEN Research Products; $200 \mathrm{mCi} / \mathrm{mmol}$ ). The reaction mixture was overlaid with $5 \mathrm{ml}$ of Econofluor (Dupont, NEN) and incubated in a scintillation vial at $37^{\circ} \mathrm{C}$. Vials were usually counted after 4,8 , and $24 \mathrm{~h}$ of incubation.

CAT expression in NIH 3T3 cells. NIH 3T3 cells were transfected with $10 \mu \mathrm{g}$ of plasmid DNA along with $10 \mu \mathrm{g}$ of carrier DNA as previously described (9). Cells were harvested after $40 \mathrm{~h}$ of incubation and lysed by freeze-thawing. CAT activity was assayed by thin-layer chromatography as described by Gorman et al. (12).

Reverse transcription-polymerase chain reaction. RNA was extracted by a modification of the guanidinium thiocyanatecesium chloride procedure (8). Briefly, injected oocytes were cultured for $24 \mathrm{~h}$, washed with DPBS, lysed in $1 \mathrm{ml}$ of $5 \mathrm{M}$ guanidinium thiocyanate solution containing $30 \mu \mathrm{g}$ of NIH 3T3 RNA as carrier, layered over $1 \mathrm{ml}$ of $5.7 \mathrm{M} \mathrm{CsCl}$, and centrifuged in a TLA 100.3 rotor for $5 \mathrm{~h}$ at $80,000 \mathrm{rpm}$ in a Beckman TL-100 tabletop ultracentrifuge. The pellet was

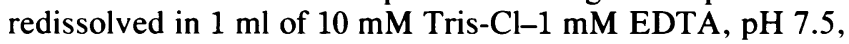
layered over $1 \mathrm{ml}$ of $5.7 \mathrm{M} \mathrm{CsCl}$, and recentrifuged under similar conditions. The RNA pellet was redissolved in diethylpyrocarbonate-treated water, ethanol precipitated, and washed with $80 \%$ ethanol. The pellet was air dried, redis-

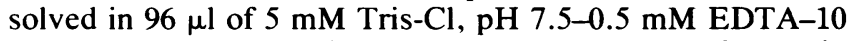
$\mathrm{mM} \mathrm{MgCl} 2-0.1 \mathrm{mM}$ dithiothreitol (DTT)-40 U of RNasin (Promega). Four units of RNase-free DNase (Promega) was added, and the ample was incubated for $1 \mathrm{~h}$ at $37^{\circ} \mathrm{C}$. RNA was extracted $\therefore$ ice with phenol-chloroform and twice with chloroform, pl . pitated twice with ethanol, washed twice 
with $80 \%$ ethanol, air dried, and redissolved in $20 \mu \mathrm{l}$ of diethylpyrocarbonate-treated water.

To synthesize cDNA, a part of the RNA sample was heated at $90^{\circ} \mathrm{C}$ for $5 \mathrm{~min}$ and quickly chilled on ice. This was added to a reaction mixture containing $1 \times$ GeneAmp PCR buffer (Cetus), $0.5 \mathrm{mM}$ each of the four dNTPs, $40 \mathrm{U}$ of RNasin, $400 \mathrm{ng}$ of oligo(dT), and $1 \mathrm{mM}$ dithiothreitol in a final volume of $25 \mu \mathrm{l}$. The RNA was incubated with $25 \mathrm{U}$ of avian myeloblastosis virus reverse transcriptase (RT) (Promega) at $40^{\circ} \mathrm{C}$ for $75 \mathrm{~min}$, heated at $90^{\circ} \mathrm{C}$ for $5 \mathrm{~min}$, and quickly chilled on ice.

Amplification of $\mathrm{cDNAs}$ by the polymerase chain reaction (PCR) was performed in a $100-\mu l$ reaction mixture containing $1 \times$ GeneAmp PCR buffer, 100 pmol of each primer, $0.2 \mathrm{mM}$ of each of the four deoxynucleoside triphosphates, $2.5 \mathrm{U}$ of AmpliTaq DNA Polymerase (Cetus), and 1 to $5 \mu$ l of the RT products. The primers used were $5^{\prime}$-ACCACTGCTCCCAT TCATCAGTTCCATAGG-3' and 5'-GTCTGTGATGGCTT CCATGTCGGCAGAATG-3', which span the SV40 $t$ intron in the CAT plasmids (12), and 5'-GTGGTTCTCAGCA GGTT-3' and 5'-GTCAGCGTGCAAGCATT-3', which are homologous to sequences in exons 8 and 11 of c-raf-1 (4). The reaction mixture was overlaid with mineral oil and amplified for 40 cycles by using the following conditions: denaturation at $94^{\circ} \mathrm{C}$ for $1 \mathrm{~min}$, annealing at $62^{\circ} \mathrm{C}$ for $1 \mathrm{~min}$, and extension at $72^{\circ} \mathrm{C}$ for $2 \mathrm{~min}$. Products were analyzed by electrophoresis in a $5 \%$ polyacrylamide gel.

\section{RESULTS}

c-mos transcription initiation site. An earlier study (30) had mapped the transcription initiation sites of the c-mos gene in mouse ovary at about $70 \mathrm{bp}$ upstream of the first ATG in the c-mos open reading frame. Since this was only an approximation, which the authors indicated to be $\pm 5 \mathrm{bp}$, we performed a primer extension analysis to more precisely determine the c-mos transcription initiation site (Fig. 1). A labeled synthetic oligonucleotide primer was annealed to ovary RNA and extended with RT. A sequencing ladder obtained by using the same primer and the relevant region of the c-mos gene was electrophoresed alongside the extended products. The major transcription site was mapped at 53 nucleotides upstream of the mos ATG. In repetitions of the experiment there were variations in the intensities of the weaker bands, some of which may represent minor initiation sites, but 53 bp upstream of the ATG remained the major transcription start site.

Transient expression assays in injected oocytes. In order to identify the regulatory elements in the 5 '-flanking sequences of the c-mos gene, we employed an assay to study transient expression of plasmid DNA. in injected murine oocytes (6, 7). In preliminary experiments, germinal vesicles (nuclei) of growing transcriptionally active mouse oocytes were injected with the plasmid pSV3CAT, in which the SV40 early promoter was fused to a CAT reporter gene. Approximately 50,000 DNA molecules were injected into each oocyte. The injected oocytes were cultured for $48 \mathrm{~h}$, and surviving oocytes were assayed for CAT activity by using a scintillation vial procedure (described in Materials and Methods). Oocytes injected with pSV3CAT produced approximately 20-fold-higher levels of CAT than did control oocytes that were either uninjected or injected with the promoterless plasmid pSVOCAT (Fig. 2).

We next determined whether the 5 '-flanking sequences of c-mos could similarly promote CAT expression in mouse oocytes. Plasmids pmos 2400 and pmos 731 were constructed
A

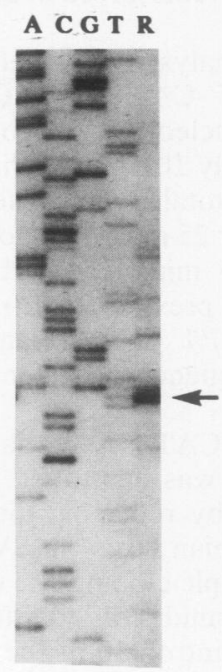

B

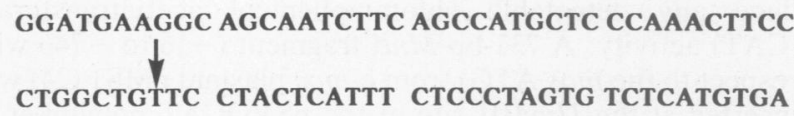

\section{CTGTCCCATC TGAGGGTGTA ATCG}

FIG. 1. Identification of transcription initiation site(s) of c-mos. (A) RNA was prepared from ovaries of 20- to 23-day-old mice, and primer extension was carried out using a c-mos-specific synthetic primer (lane R). A sequencing ladder obtained from the c-mos gene in plasmid pMS1 by the dideoxynucleotide termination method with the same oligonucleotide primer was used as the marker (lanes $\mathrm{A}, \mathrm{C}$, $\mathrm{G}$, and T). (B) 100 nucleotides of 5'-flanking sequence of c-mos; the major transcription initiation site is indicated by the arrow.

by inserting either a 2.4-kb or a 731-bp fragment of the c-mos $5^{\prime}$-flanking region into pSVOCAT. Each of these plasmids was injected into growing oocytes, and CAT activity was assayed as described above. Both mosCAT plasmids produced similar levels of CAT activity, which were about $50 \%$ of that produced by pSV3CAT (Fig. 2). It thus appeared that sequences within a 731-bp region upstream of the c-mos ATG could efficiently promote gene expression in oocytes.

Since normal expression of the c-mos gene is highly cell specific (31), it was of interest to determine whether the two mosCAT plasmids were expressed in NIH $3 \mathrm{~T} 3$ cells (Fig. 3). In contrast to the results obtained in oocytes, neither mosCAT plasmid produced significant CAT activity in transfected NIH 3T3 cells, whereas pSV3CAT was efficiently expressed. It therefore appeared that a 731-bp fragment from the 5'-flanking region of c-mos was sufficient to direct appropriate oocyte-specific expression.

Deletion analysis of c-mos upstream sequences. We next sought to identify regulatory elements within the c-mos 5 -flanking sequences by deletion analysis. Since the c-mos fragment was cloned into a multiple cloning site in pmos 731 (Fig. 4), suitable restriction sites were available to generate deletions from either end. Deletions from the 5' end were generated by linearizing pmos 731 with $\mathrm{BamHI}$ and digesting with BAL 31 nuclease. Each of the plasmids derived from 


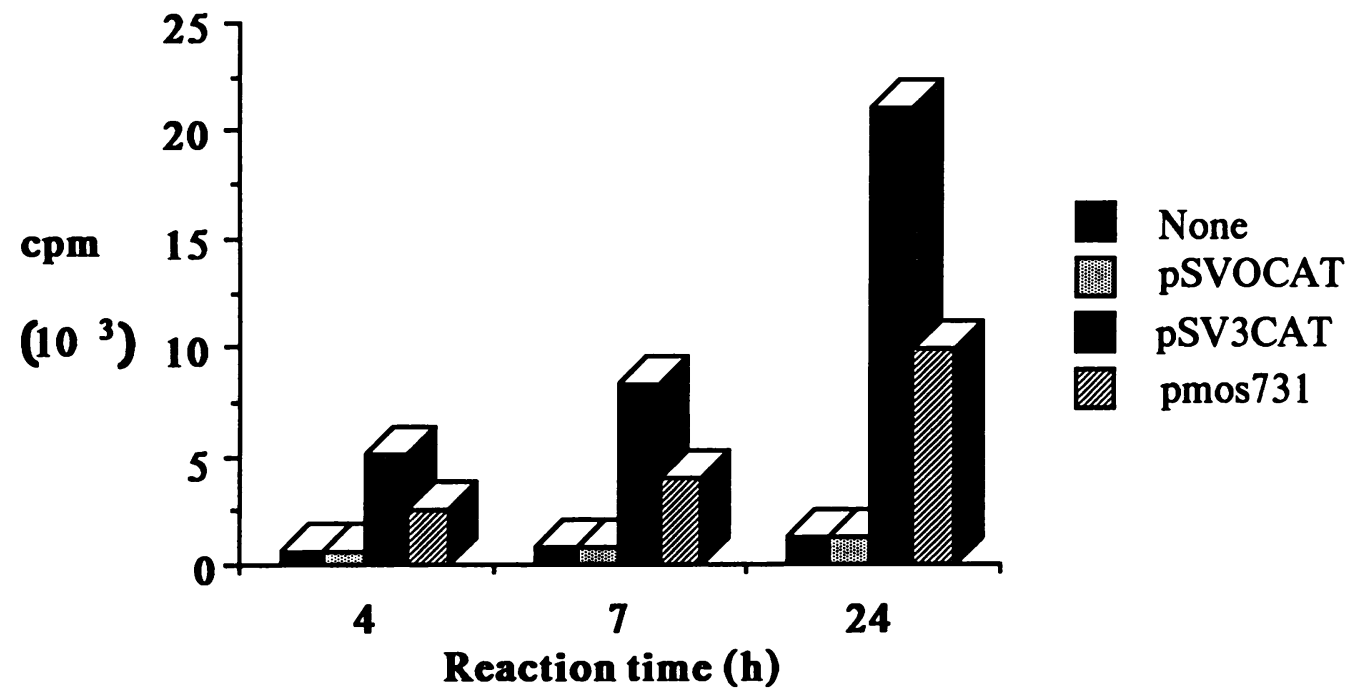

FIG. 2. CAT assay of injected oocytes. Growing oocytes were isolated from 18- to 20-day-old female B6SJL mice and microinjected with the indicated CAT reporter plasmids. The injected oocytes were cultured for $48 \mathrm{~h}$, and surviving oocytes (50 to $70 \%$ of those injected) were assayed for CAT activity by using a scintillation vial method. Reaction times are indicated. Each sample contained 12 to 15 oocytes. The plasmids used were pSVOCAT (no promoter), pSV3CAT (SV40 early promoter), and pmos731 (731 bp of c-mos 5'-flanking sequence).

these deletions was then assayed for promoter activity by injection into oocytes (Fig. 5). Surprisingly, the entire sequence up to 21 nucleotides upstream of the transcription initiation site could be removed without any significant loss of CAT activity. Deletions as close to the major transcription start site as -4 and -1 still retained some activity, although at a reduced level, whereas a deletion across the transcription start site to +11 abolished CAT activity. Therefore, very little, if any, c-mos sequence $5^{\prime}$ to the transcription initiation site was required for expression in oocytes.

Identification of a regulatory element in the untranslated leader sequence. In order to determine whether there were any regulatory sequences downstream from the c-mos tran-

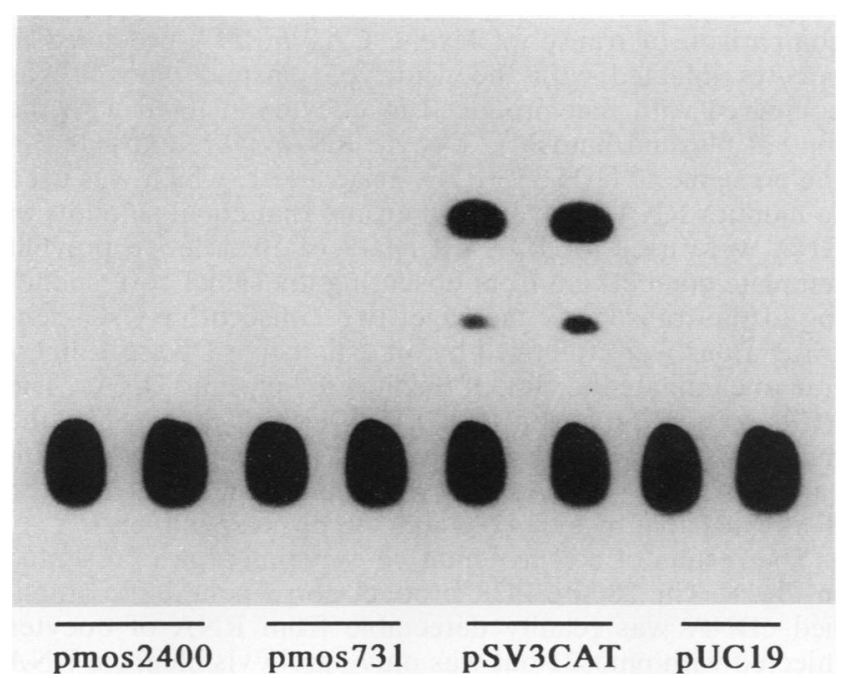

FIG. 3. CAT assay of transfected NIH 3T3 cells. NIH 3T3 cells were transfected with $10 \mu \mathrm{g}$ of the indicated plasmid DNAs. After 40 $h$ of incubation, cells were harvested and the CAT assay was performed by thin-layer chromatography. The reaction time was $4 \mathrm{~h}$. Each lane represents cells from one $60-\mathrm{mm}$ plate. scription initiation site, we performed a deletion analysis of the c-mos untranslated leader sequences, which consist of 53 nucleotides upstream of the ATG. The plasmid pmos21 extends 38 nucleotides downstream of the transcription start site and is missing 15 nucleotides immediately upstream of the ATG. We therefore initially replaced the c-mos sequences of this plasmid with a synthetic oligonucleotide spanning the entire c-mos sequence from 21 nucleotides upstream of the transcription start site to the ATG. This, however, had no significant effect on promoter activity (Fig. $6)$. Then, while 21 nucleotides upstream of the transcription start site were maintained as the $5^{\prime}$ end of the sequence, BAL 31 was used to create further deletions from the 3 ' end

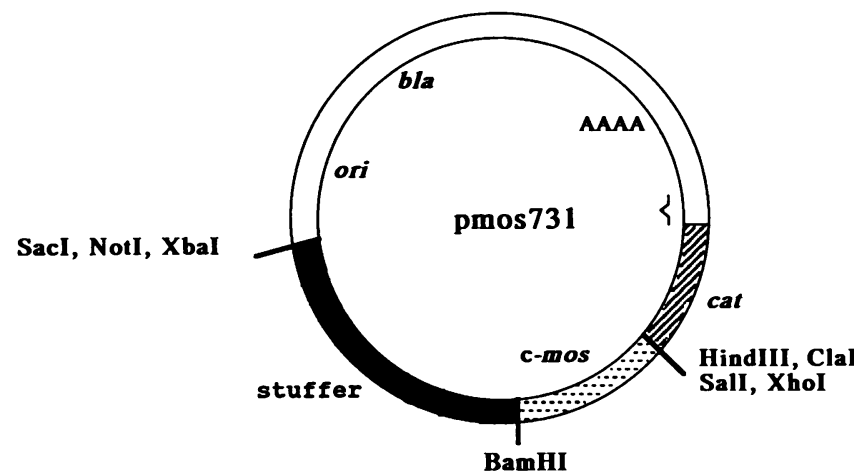

FIG. 4. Schematic diagram of plasmid pmos731. The 6.9-kb plasmid was derived from pSV3CAT by replacing the SV40 early promoter with a 731-bp $M n l I$ fragment from the 5'-flanking sequence of c-mos (nucleotides -693 to +38 with respect to the transcription initiation site) in the same orientation as the CAT gene. A stuffer fragment, which is a 1.6-kb XbaI-BamHI fragment from c-raf-1 intron 10 , has been inserted 5 ' to the c-mos sequence. The plasmid also contains the SV40 polyadenylation signal (AAAA) and the t-intron $(\sim)$ ) in addition to the pBR322 origin of replication (ori) and ampicillin resistance gene (bla). Bam HI and SalI restriction sites were utilized to make deletions from the $5^{\prime}$ and $3^{\prime}$ ends of the c-mos fragment with BAL 31 nuclease. 


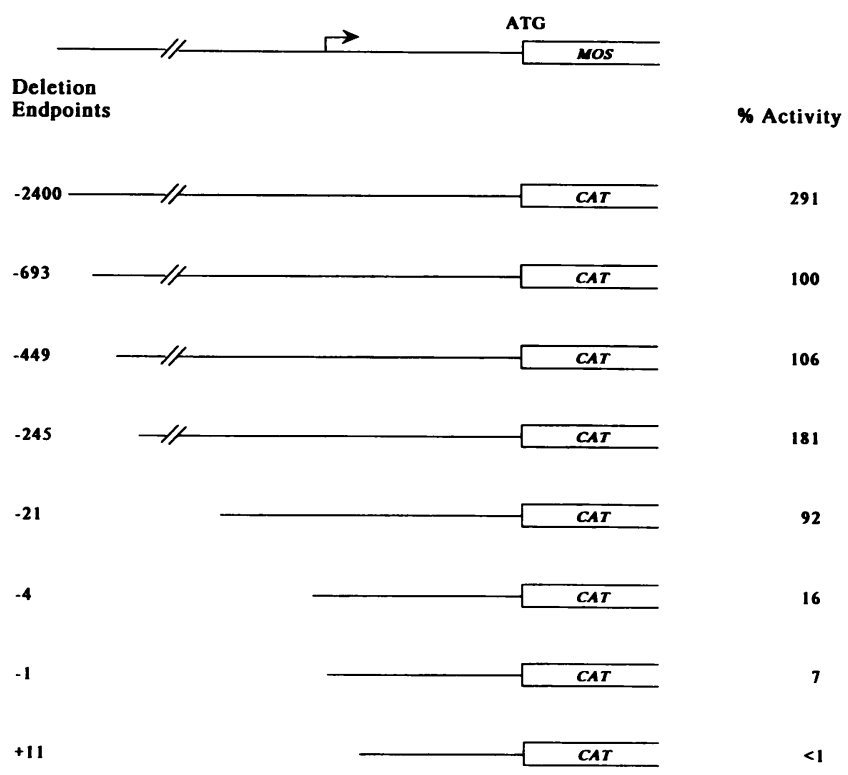

FIG. 5. Effect of $5^{\prime}$ deletions on the CAT activity of injected oocytes. Growing oocytes were injected with a series of deletions from the $5^{\prime}$ end of the 2.4-kb $5^{\prime}$-flanking sequence of c-mos, cultured for $48 \mathrm{~h}$, and assayed for CAT activity. Deletion endpoints and relative CAT activities are shown for each construct. Deletion endpoints are numbered with respect to the transcription start site, which is indicated on the top line. CAT activity from pmos731 (deletion endpoint, -693) was taken as $100 \%$ (approximately 9,000 $\mathrm{cpm} / 15$ oocytes per $24 \mathrm{~h}$ of reaction).

of pmos21. Such deletions extending to 4 and 19 nucleotides downstream of the transcription start site led to a 10- to 20-fold reduction in CAT expression (Fig. 6), indicating that untranslated leader sequences immediately downstream of the transcription initiation site contribute to c-mos promoter activity.

Examination of the untranslated leader sequence for known cis-acting regulatory elements revealed only a weak consensus sequence ( $5^{\prime}$-PyPyCAPyPyPyPyPy-3') between 7 and $15 \mathrm{bp}$ downstream of the transcription initiation site (Fig. 7). This sequence forms a part of the initiator (Inr) element (36) present in some TATA-containing genes as well as in TATA-lacking genes. To determine whether this sequence contributed to expression of c-mos, which lacks a TATA box, we used synthetic oligonucleotides to create clustered point mutations at different regions of the c-mos

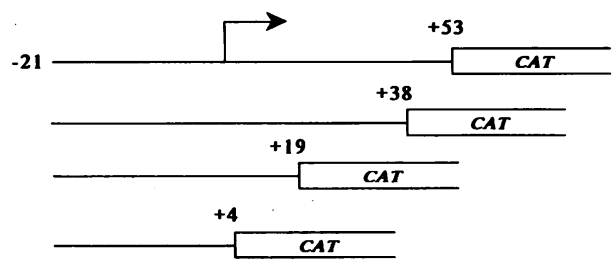

\% Activity

139

100

10

FIG. 6. Effect of deletions in the transcribed leader sequence. Deletions were made from the $3^{\prime}$ end of the c-mos sequence of pmos21. The plasmids thus generated were injected into growing oocytes, and CAT activity was assayed as described for Fig. 5. CAT activity relative to that obtained from pmos 21 is shown beside each construct. Nucleotide numbering is with respect to the major transcription start site.

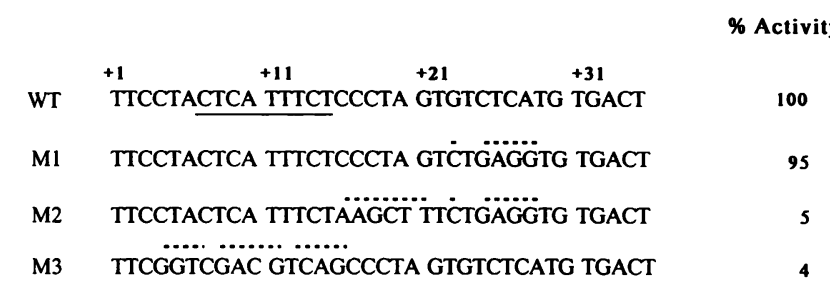

FIG. 7. Oligonucleotide-directed site-specific mutagenesis of the untranslated leader sequence of c-mos. The wild-type sequence shown in the uppermost line is present in the plasmid pmos21, which was used to generate the mutants M1, M2, and M3. Substitutions are shown by dashes over the nucleotides. Percent CAT activity relative to pmos 21 is shown. Nucleotides are numbered with respect to the c-mos transcription start site. The Inr consensus sequence is underlined.

untranslated leader sequences. These mutants were then tested for promoter activity in injected oocytes (Fig. 7). The mutant M1, which had five of six bases altered between 23 and 28 bp downstream of the transcription initiation site, did not display any significant reduction in CAT activity. However, when the mutations in M1 were extended to include six more altered bases between 16 and 21 nucleotides downstream of the transcription initiation site, CAT expression in injected oocytes was reduced approximately 20 -fold. A similar reduction in promoter activity was observed when 10 of 12 bases were mutated between 4 and 15 bp downstream of the transcription start site (mutant M3). These results indicate that sequences extending about 20 bp downstream of the transcription start site, including the Inr consensus sequence 5'-PyPyCAPyPyPyPyPy-3', augment c-mos expression in mouse oocytes.

c-mos expression is regulated at the level of transcription. Since the regulatory sequences described above are present within c-mos RNA, we sought to determine whether the observed differences in CAT expression were due to regulation at the transcriptional level. Because of the limited material provided by injected mouse oocytes, we utilized reverse transcription of oocyte RNAs coupled to PCR amplification of the resulting cDNAs to obtain an approximate comparison of transcript levels. CAT mRNA produced in oocytes injected with the wild-type plasmid pmos 21 was compared with that produced in oocytes injected with the mutant plasmid pmosM3. Oocyte RNAs were extracted in the presence of NIH 3T3 RNA as a carrier, which was used to monitor RNA recovery and ensure that equal amounts of RNA were used for RT-PCR analysis. In order to prevent template competition from obscuring the signal corresponding to the transcribed message, two consecutive $\mathrm{CsCl}$ centrifugations were followed by an exhaustive DNase I digestion to eliminate the bulk of the injected plasmid DNAs. The PCR primers spanned the SV40 intron present in the mosCAT plasmids, so the products resulting from amplification of CAT cDNAs and residual plasmid DNAs were distinguishable by size ( 280 and $346 \mathrm{bp}$, respectively).

The results of a representative experiment are presented in Fig. 8. The 280-bp PCR product corresponding to amplified cDNA was readily detectable from RNA of oocytes injected with pmos 21 but was only barely visible from RNA of oocytes injected with pmosM3 (Fig. 8A). In contrast, the 346-bp product arising from amplification of residual plasmid DNA was detected at similar levels in both samples, serving as an internal PCR control. Control experiments demonstrated that only the 346 -bp product was detected following 
A

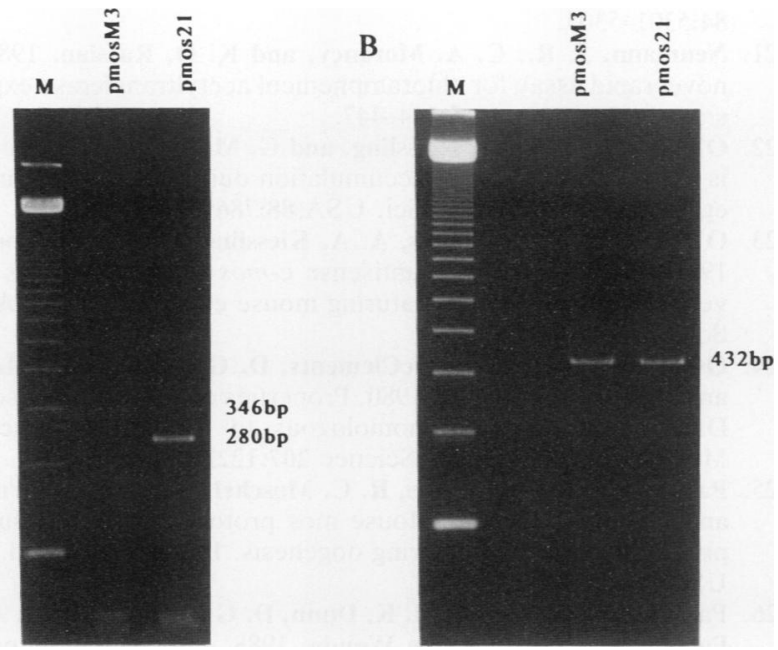

FIG. 8. Comparison of CAT mRNA levels in injected oocytes. Oocytes were injected with either the wild-type plasmid pmos 21 or the mutant plasmid pmosM3 and cultured for $24 \mathrm{~h}$. RNA was purified from equal numbers of injected oocytes ( 25 in each group) by using $30 \mu \mathrm{g}$ of NIH 3T3 RNA as the carrier. RNA recovery was monitored by electrophoresis in a formaldehyde-agarose gel. Equal amounts of RNA were reverse transcribed, and the cDNAs were amplified with primers either spanning the SV40 t-intron in CAT plasmids (A) or homologous to sequences in exons 8 and 11 of c-raf-1 (B). Equal portions of the amplified products were electrophoresed in a $5 \%$ polyacrylamide gel. Each lane corresponds to RNA from approximately one-half of an oocyte. The 280-bp products from cDNA, the 346-bp products from plasmid DNA obtained with the CAT/t-intron primers, and the 432-bp products generated by the c-raf-1 primers from cDNA have been indicated. M, 123-bp DNA ladder (BRL).

amplification of plasmid DNA in the presence of NIH 3T3 carrier (data not shown). In addition, parallel RT-PCR reactions yielded similar levels of amplification of c-raf-1 RNA (presumably from the NIH 3T3 carrier) from both samples (Fig. 8B). Similar results were obtained in three independent repeats of the experiment, each utilizing different sets of injected oocytes. It thus appears that sequences downstream of the initiation site regulate c-mos transcription, although it is recognized that the RT-PCR analysis measures steady-state levels of RNA rather than rates of RNA synthesis.

\section{DISCUSSION}

The c-mos proto-oncogene is specifically expressed in mouse oocytes, where it functions in the meiotic cell cycle. The sequences that regulate c-mos transcription, or that of other genes expressed as maternal RNAs, have not been defined. We have therefore employed a microinjection assay using the CAT reporter gene to identify the sequence elements that promote c-mos transcription in growing mouse oocytes.

Deletion analysis revealed that sequences up to $20 \mathrm{bp}$ upstream of the phajor transcription start site could be removed without any significant loss of CAT expression. Promoter activity only decreased when these deletions extended to within a few nucleotides of the transcription initiation site. Thus, very little, if any, sequence upstream of the transcription start site was required for c-mos expression in oocytes. These results, however, do not exclude the possibility that additional upstream sequences are important for transcription and cell-specific regulation of the endogenous c-mos gene. Indeed, upstream regulatory sequences that inhibit c-mos expression in NIH 3T3 cells have recently been identified (unpublished observations).

On the other hand, c-mos sequences within 20 nucleotides downstream of the transcription initiation site were required for efficient expression in microinjected oocytes. These sequences included an element with the consensus sequence 5'-PyPyCAPyPyPyPyPy-3'. This sequence forms part of the Inr element, recently defined in the terminal deoxynucleotidyltransferase gene (36). Site-specific mutations of nucleotides within or immediately adjacent to the Inr consensus sequence resulted in a dramatic reduction in c-mos promoter activity. Utilizing a sensitive RT-PCR technique, we were able to show that this regulation was manifest at the level of transcription. It thus appears that efficient c-mos transcription in oocytes is directed by sequences surrounding and immediately downstream of the transcription start site, including an Inr-related element.

Inr-related elements are found both among TATA-containing and TATA-lacking genes $(13,36)$. The c-mos promoter does not contain a TATA box, nor does it contain $\mathrm{GC}$-rich regions characteristic of housekeeping genes. Other promoters lacking TATA elements and GC-rich sequences are, like c-mos, often expressed in a regulated manner during development or differentiation. These genes include mouse terminal deoxynucleotidyltransferase (36), human porphobilinogen deaminase (2), and the Drosophila genes Ultrabithorax (3), engrailed (37), and Antennapedia (27). Transcription of these genes, like that described here for c-mos, appears to be regulated by sequences near the transcription start site and within the transcribed leader. The terminal deoxynucleotidyltransferase promoter also includes the Inr consensus sequence 5'-PyPyCAPyPyPyPyPy-3'. In this case, however, transcription initiates at the $A$ of this consensus sequence, whereas the major c-mos transcription start site is 9 nucleotides further upstream. The Inr-related element we have recognized in c-mos is thus capable of promoting transcription from a distinct start site, which may or may not be a part of the Inr element itself.

Other sequences surrounding the transcription site may also play a role in regulating c-mos transcription. For example, it is noteworthy that the c-mos sequence 5'-CTGGCT GT $-3^{\prime}$ (nucleotides -7 to +1 ) is closely related to regulatory elements that have been identified downstream of several other eucaryotic promoters, including the downstream activating protein-binding site of the SV40 late promoter (1). The potential roles of this and other c-mos promoter sequences remain to be addressed.

Our results indicate that efficient c-mos expression in mouse oocytes is directed by a very simple promoter, including only sequences immediately surrounding the transcription start site. Such a minimal promoter structure may be consistent with other studies indicating that SV40 or polyomavirus enhancers are not required for the utilization of SV40 or thymidine kinase promoters in injected murine oocytes $(6,17)$. It will obviously be of interest to compare the promoters of other genes that are specifically expressed in mouse oocytes, such as the zona pellucida genes $(16,29$, 32 ), with that of c-mos.

\section{ACKNOWLEDGMENTS}

We thank N. DeLuca for the pSV3CAT plasmid.

This investigation was supported by National Institutes of Health 
Grant HD26594, NIH Fellowship CA08667, and an Investigator Award from the Claudia Adams Barr Program for Cancer Research.

\section{REFERENCES}

1. Ayer, D. E., and W. S. Dynan. 1990. A downstream-elementbinding factor facilitates assembly of a functional preinitiation complex at the simian virus $\mathbf{4 0}$ major late promoter. Mol. Cell. Biol. 10:3635-3645.

2. Beaupain, D., J. F. Eleouet, and P. H. Romeo. 1990. Initiation of transcription of the erythroid promoter of the porphobilinogen deaminase gene is regulated by a cis-acting sequence around the cap site. Nucleic Acids Res. 18:6509-6515.

3. Biggin, M. D., and R. Tjian. 1988. Transcription factors that activate the Ultrabithorax promoter in developmentally staged extracts. Cell 53:699-711.

4. Bonner, T. I., S. B. Kerby, P. Sutrave, M. A. Gunnell, G. Mark, and U. R. Rapp. 1985. Structure and biological activity of human homologs of the raflmil oncogene. Mol. Cell. Biol. 5:1400-1407.

5. Cathala, G., J.-F. Savouret, B. Mendez, B. L. West, M. Karin, J. A. Martial, and J. D. Baxter. 1983. A method for isolation of intact, translationally active ribonucleic acid. DNA 2:329-335.

6. Chalifour, L. E., D. O. Wirak, U. Hansen, P. M. Wassarman, and M. L. DePamphilis. 1987. Cis- and trans-acting sequences required for expression of simian virus $\mathbf{4 0}$ genes in mouse oocytes. Genes Dev. 1:1096-1106.

7. Chalifour, L. E., D. O. Wirak, P. M. Wassarman, and M. L. DePamphilis. 1986. Expression of simian virus 40 early and late genes in mouse oocytes and embryos. J. Virol. 59:619-627.

8. Chirgwin, J. M., A. E. Przybyla, R. J. McDonald, and W. J. Rutter. 1979. Isolation of biologically active ribonucleic acid from sources enriched in ribonuclease. Biochemistry 18:5294 5299.

9. Copeland, N. G., and G. M. Cooper. 1979. Transfection by exogenous and endogenous murine retrovirus DNAs. Cell 16: 347-356.

10. Goldman, D. S., A. A. Kiessling, and G. M. Cooper. 1988 Post-transcriptional processing suggests that c-mos functions as a maternal message in mouse eggs. Oncogene 3:159-162.

11. Goldman, D. S., A. A. Kiessling, C. F. Millette, and G. M. Cooper. 1987. Expression of c-mos RNA in germ cells of male and female mice. Proc. Natl. Acad. Sci. USA 84:4509-4513.

12. Gorman, C. M., L. F. Moffat, and B. H. Howard. 1982. Recombinant genomes which express chloramphenicol acetyltransferase in mammalian cells. Mol. Cell. Biol. 2:1044-1051.

13. Hariharan, N., and R. P. Perry. 1990. Functional dissection of a mouse ribosomal protein promoter: significance of the polypyrimidine initiator and an element in the TATA-box region. Proc. Natl. Acad. Sci. USA 87:1526-1530.

14. John, D. P., and A. A. Kiessling. 1988. Improved pronuclear mouse embryo development over an extended $\mathrm{pH}$ range in Ham's F-10 medium without protein. Fertil. Steril. 49:150-155.

15. Kingston, R. E. 1987. Primer extension, p. 4.8.1-4.8.3. In E. M Ausubel, R. Brent, R. E. Kingston, D. D. Moore, J. G. Seidman, J. E. Smith, and K. Struhl (ed.), Current protocols in molecular biology. Wiley-Interscience, New York.

16. Liang, L.-F., S. M. Chamow, and J. Dean. 1990. Oocyte-specific expression of mouse ZP-2: developmental regulation of the zona pellucida genes. Mol. Cell. Biol. 10:1507-1515.

17. Martinez-Salas, E., E. Linney, J. Hassell, and M. L. DePamphilis. 1989. The need for enhancers in gene expression first appears during mouse development with formation of the zygotic nucleus. Genes Dev. 3:1493-1506.

18. Mehta, T. S., and A. A. Kiessling. 1990. Development potential of mouse embryos conceived in vitro and cultured in EDTA with or without amino acids or serum. Biol. Reprod. 43:600-606.

19. Mutter, G. L., G. S. Grill, and D. J. Wolgemuth. 1988. Evidence for the involvement of the proto-oncogene c-mos in mammalian meiotic maturation and possibly very early embryogenesis. EMBO J. 7:683-689.

20. Mutter, G. L., and D. J. Wolgemuth. 1987. Distinct developmental patterns of c-mos protooncogene expression in female and male mouse germ cells. Proc. Natl. Acad. Sci. USA
84:5301-5305.

21. Neumann, J. R., C. A. Morency, and K. O. Russian. 1987. A novel rapid assay for chloramphenicol acetyltransferase expression. BioTechniques 5:444-447.

22. O'Keefe, S. J., A. A. Kiessling, and G. M. Cooper. 1991. c-mos is required for cyclin $\mathbf{B}$ accumulation during meiosis of mouse eggs. Proc. Natl. Acad. Sci. USA 88:7869-7872.

23. O'Keefe, S. J., H. Wolfes, A. A. Kiessling, and G. M. Cooper. 1989. Microinjection of antisense c-mos oligonucleotides prevents meiosis II in the maturing mouse egg. Proc. Natl. Acad. Sci. USA 86:7038-7042.

24. Oskarsson, M., W. L. McClements, D. G. Blair, J. V. Maizel, and G. F. Vande Woude. 1980. Properties of a normal mouse cell DNA sequence (sarc) homologous to the src sequence of Moloney sarcoma virus. Science 207:1222-1224.

25. Paules, R. S., R. Buccione, R. C. Moschel, G. F. Vande Woude, and J. J. Eppig. 1989. Mouse mos proto-oncogene product is present and functions during oogenesis. Proc. Natl. Acad. Sci. USA 66:5395-5399.

26. Paules, R. S., F. Propst, J. K. Dunn, D. G. Blair, K. Kaul, A. E. Palmer, and G. F. Vande Woude. 1988. Primate c-mos protooncogene structure and expression: transcription initiation both upstream and within the gene in a tissue-specific manner. Oncogene 3:59-68.

27. Perkins, K. K., G. M. Dailey, and R. Tjian. 1988. In vitro analysis of the antennapedia P2 promoter: identification of a new Drosophila transcription factor. Genes Dev. 2:1615-1626.

28. Peters, H. 1969. The development of the mouse ovary from birth to maturity. Acta Endocrinol. 62:98-116.

29. Philpott, C. C., M. J. Ringuette, and J. Dean. 1987. Oocytespecific expression and developmental regulation of ZP3, the sperm receptor of the mouse zona pellucida. Dev. Biol. 121: 568-575.

30. Propst, F., M. P. Rosenberg, A. Iyer, K. Kaul, and G. F. Vande Woude. 1987. c-mos proto-oncogene RNA transcripts in mouse tissues: structural features, developmental regulation, and localization in specific cell types. Mol. Cell. Biol. 7:1629-1637.

31. Propst, F., and G. F. Vande Woude. 1985. Expression of c-mos proto-oncogene transcripts in mouse tissues. Nature 315:516518.

32. Roller, R. J., R. A. Kinlock, B. Y. Hiraoka, S. S.-L. Li, and P. M. Wassarman. 1989. Gene expression during mammalian oogenesis and early embryogenesis: quantification of three messenger RNAs abundant in fully grown mouse oocytes. Development 106:251-261.

33. Sagata, N., M. Oskarsson, T. Copeland, J. Brumbaugh, and G. F. Vande Woude. 1988. Function of c-mos proto-oncogene product in meiotic maturation in Xenopus oocytes. Nature 335:519-525.

34. Sagata, N., N. Watanabe, G. F. Vande Woude, and Y. Ikawa. 1989. The c-mos proto-oncogene product is a cytostatic factor responsible for meiotic arrest in vertebrate eggs. Nature 342: 512-518.

35. Schmidt, M., M. K. Oskarsson, J. K. Dunn, D. G. Blair, S. Hughes, and G. F. Vande Woude. 1988. Chicken homolog of the mos proto-oncogene. Mol. Cell. Biol. 8:923-929.

36. Smale, S. T., and D. Baltimore. 1989. The "initiator" as a transcriptional control element. Cell 57:103-113.

37. Soeller, W. C., S. J. Poole, and T. Kornberg. 1988. In vitro transcription of the Drosophila engrailed gene. Genes Dev. 2:68-81.

38. Wassarman, P. M. 1983. Oogenesis: synthetic events in the developing mammalian eggs, p. 1-54. In J. F. Hartman (ed.), Mechanism and control of fertilization. Academic Press, New York.

39. Wassarman, P. M., and W. J. Josefowicz. 1978. Oocyte development in the mouse: an ultra-structural comparison of oocytes isolated at various stages of growth and meiotic competence. J. Morphol. 156:209-235.

40. Wood, T. G., M. L. McGeady, B. M. Baroudy, D. G. Blair, and G. F. Vande Woude. 1984. Mouse c-mos oncogene activation is prevented by upstream sequences. Proc. Natl. Acad. Sci. USA 81:7817-7821. 